\title{
Comparative analysis of SOFC-MGT top-level and new bottom- level system performance
}

\author{
QIAO Run-peng ${ }^{1,2}$, HE Jun-neng ${ }^{1,2}$, LIANG Qian-chao ${ }^{1,2}$, YANG Fan ${ }^{1,2}$, FU Da-wang ${ }^{2}$ \\ ${ }^{1}$ College of Power Engineering, Naval University of Engineering, Wuhan 430033, China; \\ ${ }^{2}$ School of intelligent automotor and engineering, Sanya institute of technology Sanya,572000, China
}

\begin{abstract}
In order to make the SOFC-MGT system more widely used, the mathematical simulation models of the SOFC-MGT top-level circulatory system and the new bottom circulatory system were first established, and then the performance of the two systems was analyzed and compared using Matlab/Simulink simulation software. The research results show that the output performance of the SOFC-MGT top-level circulation system is due to the new bottom-level circulation system, and the stack output performance of the two systems is not much different.
\end{abstract}

\section{Introduction}

SOFC-GT joint power generation system has many advantages, such as high efficiency and environmental friendliness, which will greatly improve the energy utilization rate, thus play the role of energy conservation and environmental protection. It is one of the most potential power generation methods ${ }^{[1-3]}$. At the same time SOFC-GT joint power generation system can solve the problems of power transmission, power use and maintenance in remote areas. Compared with the traditional thermal power generation mode, it has irreplaceable advantages ${ }^{[4,5]}$.

In terms of control strategy, Li Yang ${ }^{[6]}$ and others proposed that the air flow is constant, reduce gas flow ,2 SOFC stack temperature remains constant, cut GT speed ,3 fuel - air ratio, three ways of controlling fuel flow and air flow, the results show that, control mode 3 allows the system to achieve maximum efficiency in the range of $82 \% \sim 100 \%$, 2nd control mode can make the system run stably in $21 \% \sim 100 \%$ range. Wang Wei ${ }^{[6]}$ and so on analyzed 1 GT rotational speed to remain unchanged, control fuel intake flow ,2 keep SOFC stack temperature constant, to control the inlet flow of the compressor , 3 to keep the GT speed and SOFC stack temperature constant, control the intake flow of fuel in three ways.

On the basis of previous studies, this paper compares the performance of the SOFC-MGT new bottom cycle and the top cycle system to provide a reference for its market applications.

\section{Modular modeling}

\subsection{Assumptions}

During the establishment of the SOFC-MGT dynamic

\footnotetext{
a Corresponding author: runpengqiao@163.com
}

model, the following assumptions are made:

- All gases are ide

-Ignore the heat exchange between the system and the outside world

-The reforming reaction and the water gas replacement reaction are in equilibrium

- Uniform distribution of temperature, gas components and pressure in the system

-The system adopts the centralized parameter model

This cycle structure is called the SOFC-MGT top cycle if the gas after the reaction of the SOFC cathode and anode is directly fed into the turbine after catalytic combustion, as shown in Figure 2; The air is compressed by the compressor and enters the turbine through the heat exchanger. If the high temperature air discharged by the turbine passes directly into the SOFC cathode, then the tail gas after the cathode and anode reaction of the fuel cell enters the catalytic combustion chamber. SOFC-MGT new bottom cycle, as shown in Figure 1.

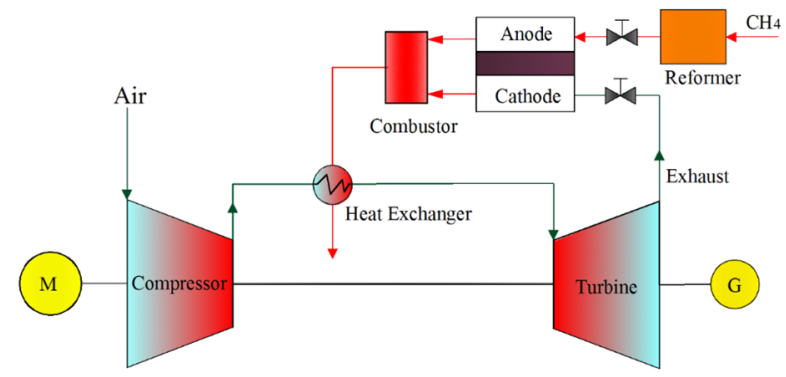

Figure 1. SOFC-MGT new bottoming hybrid cycle 


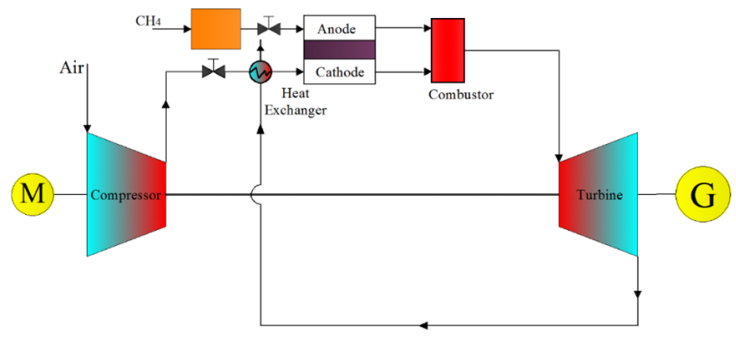

Figure 2. SOFC-MGT topping hybrid cycle

\subsection{Pre-reformer model}

In the pre-reformer, which mainly consists of the reforming reaction of methane and the water-gas replacement reaction, the chemical reaction equations are as follows ${ }^{[7]}$.

$$
\begin{aligned}
& \mathrm{CH}_{4}+\mathrm{H}_{2} \mathrm{O} \leftrightarrow \mathrm{CO}+3 \mathrm{H}_{2} \\
& \mathrm{CO}+\mathrm{H}_{2} \mathrm{O} \leftrightarrow \mathrm{CO}_{2}+\mathrm{H}_{2}
\end{aligned}
$$

From the equation for conservation of mass we get ${ }^{[8]}$ :

$$
\begin{aligned}
& \quad \frac{P_{1} V_{r e}}{R T_{1}} \frac{d x_{6, i}}{d t}=Q_{n 5, i}-Q_{n 6, i}+\bar{R}_{r e, i} \\
& \left(i \in\left[\mathrm{CH}_{4}, \mathrm{CO}, \mathrm{CO}_{2}, \mathrm{H}_{2}, \mathrm{H}_{2} \mathrm{O}\right]\right) \\
& \quad \bar{R}_{r e}=\left[-r_{r e 1}, r_{r e 1}-r_{r e 2}, r_{r e 2}, 3 r_{r e 1}+r_{r e 2},-r_{r e 1}-r_{r e 2}\right]
\end{aligned}
$$

In the above equation, $P_{1}$ is the average pressure inside the pre-reformer, $V_{r e}$ is the volume of the pre-reformer, $T_{5}$ is the average temperature of the pre-reformer, $R$ is the universal gas constant $\left(8.314 \mathrm{~J} \cdot \mathrm{mol}^{-1} \cdot \mathrm{K}^{-1}\right), x_{2, i}$ is the molar mass fraction of the exit gas, $Q_{n 1, i}$ is the molar flow rate of the inlet gas, $Q_{n 2, i}$ is the molar flow rate of the exit gas, $\bar{R}_{r e, i}$ is the molar flow rate consumed by the reforming and water-gas replacement reactions of gas $i$ in the pre-reformer, $r_{r e 1}$ represents the reforming reaction rate of methane, $r_{r e 2}$ represents the replacement reaction rate of carbon monoxide。

Assuming that both the reforming and water-gas replacement reactions have reached equilibrium, the equilibrium constants can be expressed as respectively ${ }^{[9]}$ :

$$
\begin{array}{r}
K_{r}=\exp \left(A_{1} T_{5}^{4}+B_{1} T_{5}^{3}+C_{1} T_{5}^{2}+D_{1} T_{5}+E_{1}\right) \\
K_{s}=\exp \left(A_{2} T_{5}^{4}+B_{2} T_{5}^{3}+C_{2} T_{5}^{2}+D_{2} T_{5}+E_{2}\right)
\end{array}
$$

In the above equations, $K_{r}$ and $K_{s}$ are the equilibrium constants for the reforming and water-gas replacement reactions respectively.

\subsection{Electrochemical model}

The actual voltage of a fuel cell monolith can be represented by the following equation.

$$
v_{f c}=E-\eta_{\text {ohmic }}-\eta_{\text {conc }}-\eta_{\text {act }, a}-\eta_{\text {act }, c}
$$

In the above equations, $E$ is the stack ideal reversible voltage, $\eta_{\text {ohmic }}$ is the ohmic polarization, $\eta_{\text {conc }}$ is the concentration difference polarization, $\eta_{a c t, a}$ is the anodic activation polarization, $\eta_{a c t, c}$ is the cathodic activation polarisation。According to the Nernst equation, the ideal reversible voltage of the stack is expressed $\mathrm{as}^{[10]}$ :

$$
\begin{aligned}
& E=E^{0}+\frac{R T_{\text {cell }}}{2 F} \ln \left(\frac{p_{4, H_{2}} p_{5, O_{2}}^{0.5}}{p_{4, \mathrm{H}_{2} O}}\right) \\
& E^{0}=1.2723-2.7645 \times 10^{-4} T_{\text {cell }}
\end{aligned}
$$

In the above equations, $E^{0}$ is the standard electric potential, $p_{4, H_{2}}$ is the pressure of the hydrogen at the anode outlet, $p_{4, \mathrm{H}_{2} \mathrm{O}}$ is the pressure of the water at the anode outlet, $p_{5, O_{2}}$ is the pressure of the oxygen at the cathode inlet, $T_{\text {cell }}$ is the temperature of the stack.

\subsection{Pressurised gas turbine model}

Compressor pressure ratio $\pi$ is:

$$
\pi=f_{1}\left(G_{1} \frac{p_{0} \sqrt{T_{1}}}{p_{1} \sqrt{T_{0}}}, n_{c} \frac{\sqrt{T_{0}}}{\sqrt{T_{1}}}\right)
$$

The power consumed by the compressor can be expressed as:

$$
\begin{aligned}
& N e_{C}=c_{p a} T_{1}\left(\pi^{m_{a}}-1\right) / \eta \\
& m_{a}=\left(\lambda_{a}-1\right) / \lambda_{a}
\end{aligned}
$$

\subsection{Turbine model}

The micro gas turbine uses a centripetal turbine, which has the advantages of simple structure, large enthalpy drop in a single stage and wide operating range ${ }^{[12]}$.

The turbine expansion ratio is:

$$
\varepsilon_{T}=f_{3}\left(\frac{G_{9} \sqrt{T_{9}}}{p_{9}}, \frac{n_{T}}{\sqrt{T_{9}}}\right)
$$

The turbine efficiency characteristics can be expressed as:

$$
\eta_{T}=f_{4}\left(\frac{G_{9} \sqrt{T_{9}}}{p_{9}}, \frac{n_{T}}{\sqrt{T_{9}}}\right)
$$

In the above equation, $G_{9}$ is turbine inlet flow, $p_{9}$ is turbine inlet pressure, $T_{9}$ is turbine inlet temperature, $\eta_{T}$ is turbine speed.

The work done by the turbine is:

$$
N e_{T}=c_{p a} T_{3}\left(1-\varepsilon^{-m_{a}}\right) \eta_{T}
$$

In the above equations, $T_{3}$ is the turbine inlet temperature, $\eta_{T}$ is the turbine efficiency, $\varepsilon$ is the turbine expansion ratio.

\section{Performance analysis}

The laboratory has an existing $1 \mathrm{~kW}$ solid oxide fuel cell experimental system, as shown in Figure. 3. 


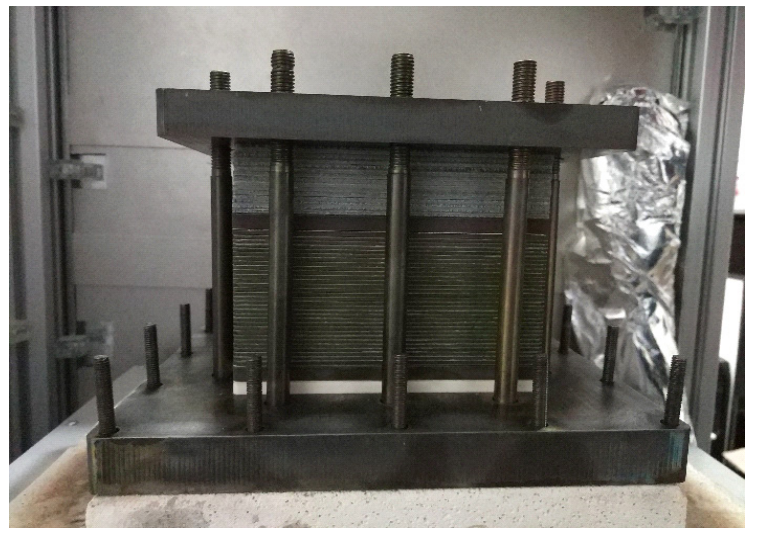

Figure 3. Solid oxide fuel cell experiment system

The set-up parameters for the SOFC-MGT hybrid power generation system model are shown in Table 1:

Table 1. Initial conditions of SOFC-MGT system operation

\begin{tabular}{|c|c|c|}
\hline Parameters & Unit & Numerical values \\
\hline $\begin{array}{l}\text { Fuel import } \\
\text { composition } x_{1, i}\end{array}$ & - & $100 \% \mathrm{CH}_{4}$ \\
\hline Fuel inlet flow $Q_{n 1}$ & $\mathrm{~mol} \cdot \mathrm{s}^{-1}$ & $2.75 \times 10^{-3}$ \\
\hline $\begin{array}{c}\text { Air import } \\
\text { composition } x_{5, i}\end{array}$ & - & $79 \% \mathrm{~N}_{2}+21 \% \mathrm{O}_{2}$ \\
\hline Air inlet flow & $\mathrm{mol} \cdot \mathrm{s}^{-1}$ & $2.37 \times 10^{-2}$ \\
\hline $\begin{array}{c}\text { Fuel inlet pressure } \\
P_{1} \\
\end{array}$ & $\mathrm{P}_{\mathrm{a}}$ & $1.013 \times 10^{5}$ \\
\hline Air inlet pressure $P_{5}$ & $\mathrm{P}_{\mathrm{a}}$ & $1.013 \times 10^{5}$ \\
\hline $\begin{array}{l}\text { Fuel inlet temperature } \\
T_{1}\end{array}$ & $\mathrm{~K}$ & 298 \\
\hline $\begin{array}{c}\text { Air inlet temperature } \\
T_{5}\end{array}$ & $\mathrm{~K}$ & 298 \\
\hline $\begin{array}{c}\text { SOFC input current } \\
i\end{array}$ & A & 43 \\
\hline $\begin{array}{l}\text { Reactor pressure loss } \\
\sigma_{s t} \\
\end{array}$ & - & $2 \%$ \\
\hline $\begin{array}{c}\text { Heat capacity of the } \\
\text { reactor } C_{s}\end{array}$ & $\mathrm{~J} \cdot \mathrm{K}^{-1}$ & 471 \\
\hline $\begin{array}{l}\text { Combustion chamber } \\
\text { pressure loss } \sigma_{b}\end{array}$ & 一 & $3 \%$ \\
\hline $\begin{array}{c}\text { Combustion chamber } \\
\text { efficiency } \eta_{b}\end{array}$ & 一 & $98 \%$ \\
\hline $\begin{array}{c}\text { Number of batteries } \\
\mathrm{N}\end{array}$ & - & 30 \\
\hline $\begin{array}{c}\text { Compressor pressure } \\
\text { ratio } \varepsilon\end{array}$ & - & 3.8 \\
\hline
\end{tabular}

Through simulation analysis, the volt-ampere characteristic curve comparison chart of the SOFC-MGT top-level cycle and the new bottom-level cycle system is obtained, as shown in Figure 4:

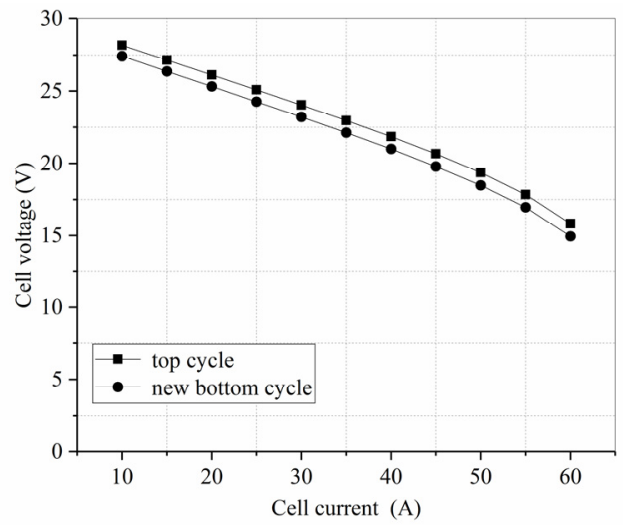

Figure 4. Comparison of the output voltage of the two systems

It can be seen from the figure that under the same initial conditions, the stack output voltage of the SOFCMGT top-level circulation system is higher than that of the new bottom-level circulation system, but the stack output voltages of the two circulation systems are not much different.

Through simulation analysis, a comparison diagram of the stack output power curve of the SOFC-MGT top-level cycle and the new bottom-level cycle system is obtained, as shown in Figure 5:

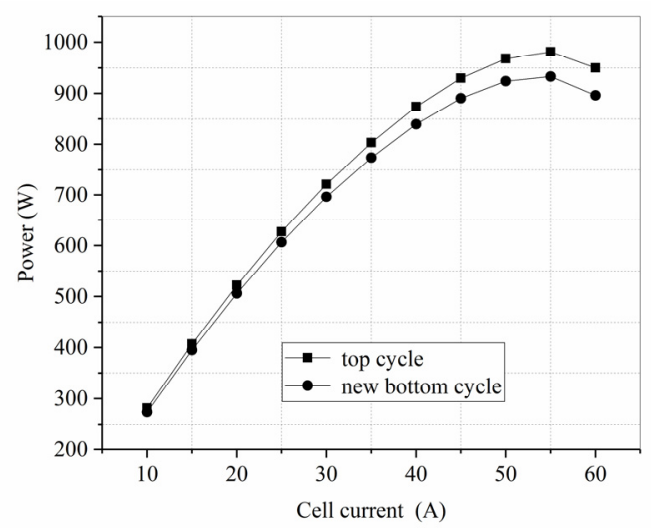

Figure 5. Comparison of the output power of the two systems

It can be seen from the figure that the output power of the SOFC-MGT top-level circulation system is higher than that of the new bottom-level circulation system. At the same time, when the output current of the stack exceeds the rated current of $43 \mathrm{~A}$, the output power of the system gradually decreases.

Through simulation analysis, a comparison diagram of the turbine output power curve between the SOFC-MGT top-level cycle and the new bottom-level cycle system is obtained, as shown in Figure 6: 


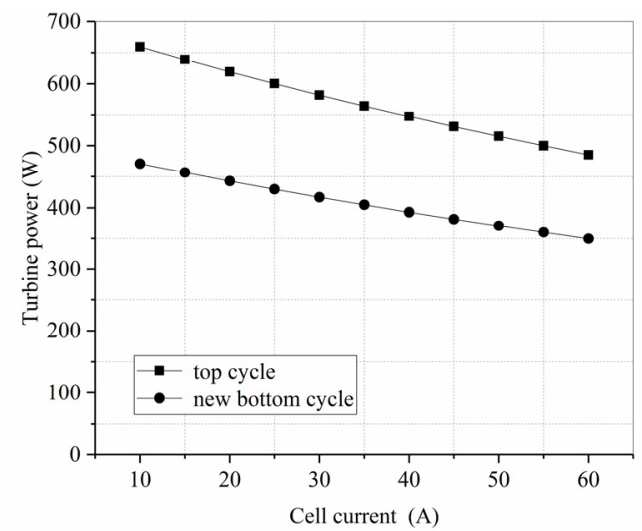

Figure 6. Comparison of the turbine output power of the two systems

It can be seen from the figure that as the stack current increases, the output power of the turbine gradually decreases, and the output power of the turbine of the SOFC-MGT top cycle is much greater than that of the bottom cycle.

Through simulation analysis, the net output power curve comparison chart of the SOFC-MGT top-level cycle and the new bottom-level cycle system is obtained, as shown in Figure 7:

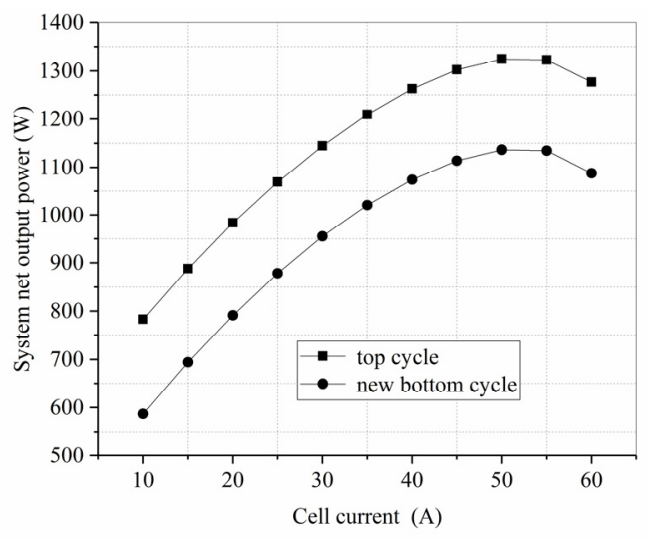

Figure 7. Comparison of the net output power of the two systems

It can be seen from the figure that as the output current of the stack increases, the net output power of the SOFCMGT top-level circulation system is much greater than that of the bottom-level circulation system.

Through simulation analysis, the efficiency curve comparison chart of SOFC-MGT top-level circulation and the new bottom-level circulation system is obtained, as shown in Figure 8:

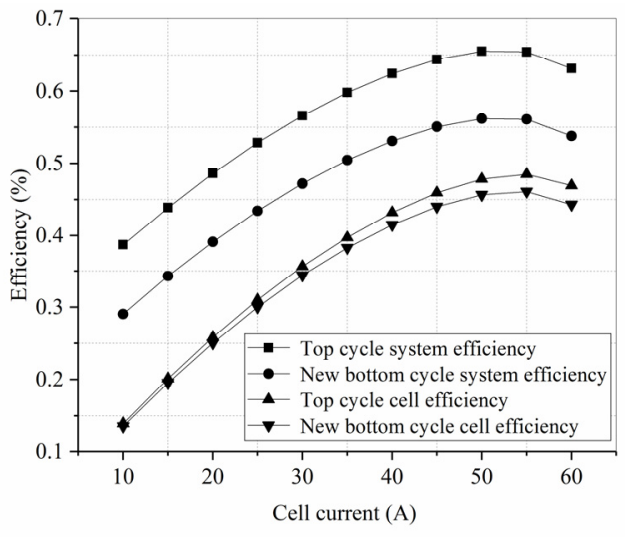

Figure 8. Comparison of the efficiency of the two systems

As can be seen from the above figure, as the output current of the stack increases, the efficiency of the SOFCMGT system first increases and then decreases. At the same time, the overall efficiency of the SOFC-MGT system is greater than the efficiency of the MGT part.

\section{Conclusion}

Through the mathematical simulation model established in this paper, the following conclusions can be drawn:

1) The system output power of the SOFC-MGT top cycle is greater than the system output power of the bottom cycle.

2) The overall output power of the SOFC-MGT system is higher than the output power of the SOFC or MGT part.

3) The SOFC-MGT top-level cycle and the new bottom-level cycle system are not much different in terms of stack output power.

\section{References}

1. Dai Anna, Xu Linfeng, Shui Anze. Research and progress of solid oxide fuel cells[J]. Bulletin of the Chinese Ceramic Society, 2015, v.34(S1):234-238.

2. Costamagna P, Magistri L, Massardo A F. Design and part-load performance of a hybrid system based on a solid oxide fuel cell reactor and a micro gas turbine $[\mathrm{J}]$. Journal of Power Sources, 2001, 96(2):352-368

3. Wu Xiaojuan. Modeling and control of solid oxide fuel cell/micro gas turbine hybrid power generation system [D]. Shanghai Jiaotong University, 2009.

4. Cinti G, Discepoli G, Sisani E, et al. SOFC Operating with Ammonia: Stack Test and System Analysis [J]. nternational Journal of Hydrogen Energy, 2016, 41 (31): 13583-13590.

5. Qingshan M, Jitian H, Kong L, et al. Thermodynamic Analysis of Combined Power Generation System Based on SOFC/GT and Transcritical Carbon Doxide Cycle [J]. International Journal of Hydrogen Energy, 2017, 42 (7): 4673-4678.

6. Li Yang, Weng Yiwu. Performance and control 
strategy analysis of solid oxide fuel cell-gas turbine hybrid power system[J]. Proceedings of the Chinese Society of Electrical Engineering, 2010, 30(35): 94100.

7. Wang Wei, Li He, Wang Xiaofang. Variable-condition control mode and performance analysis of SOFC/MGT hybrid power generation system[J]. Journal of Dalian University of Technology, 2013, 53(05): 653-658.

8. Zhu Runkai, Liang Qianchao, Yan Dong, Zhan Haiyang. Modeling and simulation study of solid oxide fuel cell and micro gas turbine combined power generation[J]. Ship Science and Technology, 2017, 39(07): 95-99.

9. E. Fontell, T. Kivisaari, N. Christiansen,et,al. Conceptual study of a $250 \mathrm{~kW}$ planar SOFC system for CHP application[J]. Journal of Power Sources, 2004.

10. Lu Y, Schaefer L . A solid oxide fuel cell system fed with hydrogen sulfide and natural gas[J]. Journal of Power Sources, 2004, 135(1-2):184-191.

11. Bove R, Lunghi P, Sammes N M . SOFC mathematic model for systems simulations. Part one: From a micro-detailed to macro-black-box model[J]. International Journal of Hydrogen Energy, 2005, 30(2):181-187.

12. Zhang Jian. Characteristic analysis of combined cycle of solid oxide fuel cell and gas turbine[D]. North China Electric Power University (Baoding), 2007 